\title{
Leveraging Sponsorships on the Internet: Activation, Congruence, and Articulation
}

\author{
Clinton S. Weeks \\ University of Queensland \\ T. Bettina Cornwell \\ University of Michigan \\ Judy C. Drennan \\ Queensland University of Technology
}

\begin{abstract}
This paper considers how the Internet can be used to leverage commercial sponsorships to enhance audience attitudes toward the sponsor. Definitions are offered that distinguish the terms leverage and activation with respect to sponsorship-linked marketing; leveraging encompasses all marketing communications collateral to the sponsorship investment, whereas activation relates to those communications that encourage interaction with the sponsor. Although activation in many instances may be limited to the immediate event-based audience, leveraging sponsorships via sponsors' Web sites enables activation at the mass-media audience level. Results of a Web site navigation experiment demonstrate that activational sponsor Web sites promote more favorable attitudes than do nonactivational Web sites. It is also shown that sponsorsponsee congruence effects generalize to the online environment, and that the effects of sponsorship articulation on audience attitudes are moderated by the commerciality of the explanation for the sponsor-sponsee relationship. Importantly, the study reveals that attitudinal effects associated with variations in leveraging, congruence, and orientation of articulation may be sustained across time. (C) 2008 Wiley Periodicals, Inc.
\end{abstract}


In relation to commercial sponsorship, the terms leverage and activation are often used interchangeably. This occurs to some extent in both the academic (e.g., Cornwell, Weeks, \& Roy, 2005; Miloch \& Lambrecht, 2006) and practitioner (e.g., Fry, 2006; Parry, 2005) literatures when reference is made to marketing communications intended to capitalize on sponsorship investments. In the practitioner literature, however, there appears to be a greater emphasis on activational communications being a subset of leverage communications (e.g., Brown, 2002; Steinberg, 2005). Specifically, the term leverage is used to describe all sponsorshiplinked marketing communications and activities collateral to the sponsorship investment, while the term activation is often reserved for those where the potential exists for audiences to interact or in some way become involved with the sponsor. If this distinction is justified, and if activational leveraging is preferred over nonactivational leveraging (i.e., where communications are processed more passively), then the challenge is to develop activation in the mass-media audience. The Internet and other communications technologies thus serve as valuable tools with which sponsors can activate their investments at the massmedia audience level.

This article establishes a clearer demarcation between the terms leverage and activation when used in relation to sponsorship and investigates the value of using the Internet as a tool to leverage sponsorships both activationally and nonactivationally to promote favorable attitudes among audiences. It considers whether these two subsets of leveraging activities vary with differing levels of sponsor-sponsee congruence (i.e., the extent to which the sponsor and sponsee share a logical relationship) and with the way the sponsor-sponsee relationship is explained to consumers (Cornwell et al., 2006, term this explanation sponsorship articulation.) A longitudinal design is employed to determine whether there are differential effects across time.

\section{PRACTITIONER ACCEPTANCE OF THE NEED TO LEVERAGE}

A recent survey by the International Events Group (IEG) indicates that sponsors estimate they will spend an average of $\$ 1.90$ on leveraging activities for every $\$ 1.00$ paid in sponsorship rights fees for 2007 (IEG, 2007). This figure represents both activational and nonactivational leverage communications. Table 1

Table 1. Estimated Leveraging Expenditure (Activational and Nonactivational) per Dollar Spent on Sponsorship Rights Fees.

\begin{tabular}{lc} 
Year & Leverage Spend per Rights Dollar \\
\hline 2001 & $\$ 1.20$ \\
2002 & $\$ 1.50$ \\
2003 & $\$ 1.70$ \\
2004 & $\$ 1.30$ \\
2005 & $\$ 1.50$ \\
2006 & $\$ 1.70$ \\
2007 & $\$ 1.90$ \\
\hline
\end{tabular}

Source: IEG, 2006, 2007; Performance Research, 2004. 
displays leveraging expenditure estimates reported since 2001, and shows that from 2004 there has been a steady increase in expected leverage spending.

Results from the IEG (2007) survey indicate that traditional advertising and public relations activities are currently the two most popular forms of sponsorship leverage (used by $79 \%$ and $76 \%$ of the sample, respectively), followed by internal communications (71\%), hospitality (67\%), direct marketing (61\%), business-to-business communications (56\%), Internet tie-ins (51\%), on-site sampling (49\%), and sales promotions (41\%). These breakdowns are informative in terms of quantifying sponsor leveraging activities and are also illustrative of the wide range of activities undertaken by firms seeking to leverage sponsorships. They do not, however, differentiate between activational and nonactivational leverage communications in the way proposed in this paper, and thus the extent to which sponsors are actively engaging consumers is not clear. The following section offers a first attempt to define the terms relevant to this issue, which may assist future work in drawing such a distinction.

\section{DEFINITIONS}

A definition of commercial sponsorship that takes leveraging potential into account is that of Quester and Thompson (2001, p. 34), which was adapted from Meenaghan (1991). These researchers describe sponsorship as "an investment, in cash or in kind, in an activity, person or event (sponsee), in return for access to the exploitable commercial potential associated with that activity, person or event by the investor (sponsor)." Derived from this definition, it is proposed here that sponsorship leverage can be defined as "the act of using collateral marketing communications to exploit the commercial potential of the association between a sponsee and sponsor."

As a subset of sponsorship leverage, activational communications (or activation, for short) can be described as "communications that promote the engagement, involvement, or participation of the sponsorship audience with the sponsor" and may include things such as event-related sweepstakes, event-driven mobile telephone competitions, and event-themed brand Web sites. In contrast, nonactivational communications can be described as "communications that promote the sponsorship association, but that may be passively processed by the sponsorship audience." These may include communications such as on-site signage, sponsor name mentions, and event-concurrent brand advertising. It should be noted that communications can be activational for the event audience while being nonactivational for the mass-media audience (e.g., activities involving event attendees such as event-based competitions, product sampling, and merchandising) if the mass-media audience is unable to interact or participate.

\section{USING THE INTERNET TO ACTIVATE AT THE MASS-MEDIA AUDIENCE LEVEL}

When sponsors aim to impact the sponsorship audience, most would envision creating impact beyond just the immediate event-based audience. In the Migala Report (2004), the Vice President of Global Sponsorships and Event Marketing 
for MasterCard voiced this idea in relation to sponsorship activation when he said of sponsees:

We're not asking them to think outside of the box as much as we are requiring them to think outside of the stadium. The team has a set audience at the stadium and that's great and valuable but how can you take it out of the stadium and into the marketplace and give us an even larger platform to market from?

One of the most readily accessible means for sponsors to activate sponsorships outside of the stadium is to incorporate event-related information or themes in their brand and corporate Web sites to engage event-interested consumers. This may sound relatively straightforward and obvious, but a surprising number of sponsors appear to overlook this tool. As noted earlier, only $51 \%$ of sponsors in the IEG (2007) survey reported using Internet tie-ins to leverage their sponsorships. Perhaps even more tellingly, an examination of sponsors listed on the official FIFA World Cup 2006 Web site (http://fifaworldcup.com) midway through the event showed that while most of the fifteen official corporate "partners" incorporated some prominent FIFA World Cup link or used a dominating graphical FIFA World Cup theme on their global home pages, two of the sponsors displayed no prominent link, nor made any reference to the event or to the sponsorship on their global home page. Given the expense that is associated with such major sponsorships, this seems to be a wasted opportunity.

\section{PREVIOUS RESEARCH}

Previous research investigating sponsors' use of leveraging communications has generally been supportive, although most of the academic literature makes no distinction between communications that actively engage audiences (activational) and communications that might be more passively processed (nonactivational). Leveraging has been described as valuable in promoting sponsorship awareness and correct sponsor identification (e.g., McDaniel \& Kinney, 1998; Quester \& Thompson, 2001), in helping to enhance sponsor image and audience attitudes (e.g., Gwinner \& Eaton, 1999; Quester \& Thompson, 2001), in creating differentiation between sponsors and nonsponsors (Cornwell, Roy, \& Steinard, 2001), and in guarding against ambush marketing (Ettore, 1993; Meenaghan, 1996).

In one field study, Quester and Thompson (2001) examined leveraging outcomes for three companies at the Adelaide Festival of the Arts held in Australia in 1998. The companies differed in the amount spent on leveraging activities using both activational and nonactivational communications (e.g., advertising, public relations activities, and sales promotions). The researchers found a clear positive relationship between leverage spending and outcomes such as audience awareness of the sponsor, and improvements between pre- and post-event attitudinal measures. Similarly, Grohs, Wagner, and Vsetecka (2004) considered leveraging activities (both activational and nonactivational) surrounding the sponsorship of the Alpine Ski World Championships held in Austria in 2001. They found that those sponsors leveraging their sponsorships to a greater extent (typically using television and print advertisements and Internet-related tie-ins) were more successful in promoting image transfer from event to brand. Thus, 
it appears that when considered as a whole, leveraging communications generally assist in promoting positive sponsorship outcomes.

One study to have specifically considered the value of activational leveraging is that of Sneath, Finney, and Close (2005). These researchers surveyed attendees at a large charity sporting event (name undisclosed) and assessed attitudes toward the title sponsor (an automobile manufacturer) among those who had visited the sponsor's event-based exhibits and among those who had not visited such exhibits. The exhibits provided attendees with the opportunity to interact with the sponsor's products and with brand representatives. Attendees visiting the sponsor's exhibits were thus exposed to activational leveraging (in that they could inspect vehicles, ask questions, and enter a competition for a new vehicle), whereas those who did not visit the exhibits were only exposed to elements of the sponsor's nonactivational communications (such as brand name and logo displays on banners, signage, T-shirts worn by volunteers, and on large-screen televisions). Results showed that those attendees exposed to activational communications rated the automobile manufacturer's sponsorship marginally more favorably, rated the automobile manufacturer itself more favorably, and were more likely to report that they would consider the automobile manufacturer at the time of their next vehicle purchase. Thus, overall it appears that while leveraging activities in general promote positive sponsorship outcomes, those that directly engage audiences generate more positive outcomes than those that can be processed more passively.

\section{HYPOTHESES}

In the current study, a Web site navigation task is employed and several hypotheses are tested. The first hypothesis relates to activational versus nonactivational leveraging communications when incorporated into sponsor Web sites. Activational Web sites are those that offer the sponsorship audience an opportunity to engage with the sponsor by providing event-related information or thematically linked tie-ins, and that encourage the event-interested consumer to interact further via the Web site. Nonactivational sponsor Web sites are those where minimal event-related information is provided, and where the event-interested consumer is given little (event-related) incentive to interact further with the sponsor via its Web site. It is hypothesized that activational Web sites will lead to more favorable audience attitudes toward the sponsor. This is because such Web sites should proactively engage the sponsorship audience, help to consolidate the sponsor-sponsee relationship in the mind of the consumer, and promote goodwill by demonstrating involvement with the event and a willingness to dedicate Web site space to it. Although most previous research in sponsorship considers either attitudes toward the sponsor as a brand or attitudes toward the sponsor as a company, both are considered in the current study since differential effects may be observed depending on the Web pages the consumer is asked to navigate, or the perspective the respondent is asked to take at test.

H1: Activational sponsor Web sites will lead to more favorable attitudinal ratings than will nonactivational sponsor Web sites for both brand- and company-level measures. 
In addition to considering leveraging differences, the current study also examines the extent to which sponsorship congruence effects generalize to the online environment, whether the nature of articulatory statements moderates attitudes toward the sponsor (articulatory statements explain a rationale for the sponsorsponsee relationship), and whether these variables interact with leveraging communications. The extent to which outcomes hold across time is also assessed.

Congruence effects in sponsorship refer to the way greater sponsor-sponsee congruence is often associated with more favorable marketing outcomes than is lesser sponsor-sponsee congruence. Congruence here relates to the extent to which the sponsor and sponsee share a logical relationship, such as would be the case with a swimwear manufacturer sponsoring a swimming event, or a clothing label sponsoring a fashion event. Greater congruence has been reported as facilitating outcomes such as sponsor identification (e.g., Cornwell et al., 2006; Grohs, Wagner, \& Vstecka, 2004; Johar \& Pham, 1999; Rodgers, 2004), positive attitude toward the sponsor (Rifon et al., 2004; Rodgers, 2004), and favorable sponsor image ratings (Becker-Olsen \& Simmons, 2005; d'Astous \& Bitz, 1995; Gwinner \& Eaton, 1999). Congruence effects are typically explained as resulting from high-congruence pairings being easier to accommodate within existing cognitive schemas, being easier to associate in memory, and/or being less prone to negative cognitive elaboration (e.g., Cornwell et al., 2006; d'Astous \& Bitz, 1995; Johar \& Pham, 1999; Rifon et al., 2004; Simmons \& Becker-Olsen, 2006). Although the exact nature of the underlying processes is still a matter of debate, it is expected that congruence effects should generalize to sponsorships leveraged in an online environment, since leveraging online is simply another means of promoting the same sponsor-sponsee association.

H2: Higher sponsor-sponsee congruence will lead to more favorable attitudinal ratings than will lower sponsor-sponsee congruence for both brand- and company-level measures.

Cornwell et al. (2006) have recently reported findings that showed that the provision of a statement articulating the sponsor-sponsee relationship to audiences can enhance memory for that relationship. Using recall as a dependent measure, the researchers demonstrated that, compared with participants who were exposed to brief press releases simply announcing an upcoming sponsorship, participants who were exposed to press releases that described a rationale for the sponsor-sponsee relationship displayed better memory for the sponsorship pairings. This was particularly the case when the sponsor-sponsee relationship had low congruence. While Cornwell et al.'s work is important and demonstrates how sponsorship awareness objectives can be achieved through the provision of articulatory statements, the current research seeks to build on this by considering how articulation can affect consumer attitudes. Although articulation may enhance memory for sponsorship information, its impact on attitudes may prove more complex, in that information which is memorable may not always be that which is favorable. The present study will examine whether the effects of articulation on consumer attitudes are moderated by the commerciality of the explanation given.

Work by Meenaghan and Shipley (1999) and Speed and Thompson (2000) suggests that activities which emphasize that the sponsor has a commercial motivation may reduce the favorability of consumer perceptions of the sponsor. 
This is in line with the ideas of Rifon et al. (2004), who suggest that when consumers perceive that sponsors have commercial motivations they tend to rate those sponsors less favorably, and work by Becker-Olsen and Simmons (2002) which shows that if the sponsor's motive is explained as being well-intentioned, both affective and behavioral responses may be enhanced. Ruth and Simonin (2006) have recently found no difference, however, in audience attitudes toward sponsors who explain their motivations as sales-driven versus those who explain their motivations as goodwill-driven, although these researchers did find that sales-driven sponsor motives were associated with poorer attitudes toward the event. To further investigate these ideas in relation to Cornwell et al.'s (2006) notion of articulation, the third hypothesis considers the provision of a commercially oriented versus a noncommercially oriented articulatory statement, and predicts that noncommercially oriented articulation will result in more favorable attitudes toward the sponsor.

H3: The presence of noncommercially oriented articulation will result in more favorable attitudinal ratings than will the presence of commercially oriented articulation for both brand- and company-level measures.

The fourth hypothesis relates to the persistence of effects across time. It is expected that attitudinal differences associated with high versus low congruence, and with noncommercially versus commercially oriented articulation will be sustained across time, since the nature of the sponsor-sponsee relationship and the articulated explanation should remain salient as key characteristics of the sponsorship. Leveraging effects should, however, vary over time. Specifically, attitudes associated with activational Web sites should remain similarly favorable while attitudes associated with nonactivational Web sites may decline. This is because the engaging nature of activation should serve to entrench positive attitudes, whereas any attitudinal benefits derived from navigation of nonactivational Web sites should only be short-lived. This is in line with Petty and Cacioppo's work (e.g., Cialdini, Petty, \& Cacioppo, 1981; Petty \& Cacioppo, 1984; Petty, Cacioppo, \& Schumann, 1983), which suggests that communications that are involving and engage audiences can promote enduring attitude change, while communications that do not involve or engage audiences may promote only temporary attitude change.

H4a: The more favorable attitudes associated with high (versus low) congruence and noncommercially (versus commercially) oriented articulation will be sustained across time.

H4b: Favorable attitudes associated with activational leveraging will be stable across time, while attitudes associated with nonactivational leveraging may decline across time.

Additional interaction effects are also expected. Specifically, it is expected that an activational Web site with noncommercially oriented articulation will lead to more favorable attitudinal ratings than will an activational Web site with commercially oriented articulation, and this will occur to a greater extent for high-congruence sponsorships than for low-congruence sponsorships. 
H5: Leverage, articulation, and congruence will interact in such a way that activational Web sites and noncommercially oriented articulation together will lead to more favorable attitudinal ratings, and this will be greater for high-congruence sponsorships.

\section{METHOD}

\section{Design}

A 2 (leverage: activational, nonactivational) $\times 2$ (congruence: high, low $) \times 2$ (articulation: commercially oriented, noncommercially oriented) $\times 2$ (time of testing: Time 1 [no delay], Time 2 [7-day delay]) mixed factorial design was used. Leverage, congruence, and articulation were between-groups variables, and time of testing was a within-groups variable. Attitude toward the brand and attitude toward the company were the two dependent variables, measured at both testing times.

\section{Participants}

The sample consisted of 114 undergraduate marketing students (64 females, 47 males, and 3 who did not specify sex). Age ranged between 17 and 34 (83.3\% were aged between 18 and 22). A convenience sample of college students was appropriate because demographically this group shares characteristics of typical Internet users who tend to be younger and college-educated (Assael, 2005).

\section{Development of Stimuli}

Sponsor and Event Selection. After several sporting goods and apparel firms were approached for permission to use their brand names, Adidas (www. adidas.com) was chosen to serve as sponsor. Two fictitious events were created that would appeal to the target group and be perceived as having greater and lesser congruence with Adidas (a track-and-field relay event and a youthoriented music festival). Although event type therefore varied with congruence, Meenaghan and Shipley (1999) note that consumers are relatively tolerant of marketing activity relating to sponsorship of both sports and mass arts (compared to social issues or causes) and so this should not be problematic.

Web Sites. Realistic Web sites were developed that contained Web pages representing the different conditions of leverage, congruence, and articulation. Eight versions of the Web site were developed in total. Each was composed of a series of three Web pages, plus a start page with brief task instructions and an end page with instructions directing participants to complete a questionnaire.

The first Web page was event-based and provided general details about the event (to introduce the congruence manipulation) together with a paragraph outlining comments from Adidas about its sponsorship of the event. This paragraph served as the platform for the articulation manipulation, and thus stated 
either that the sponsorship was being undertaken because of overlap between the event audience and Adidas's target market and that it therefore allowed access to a hard-to-reach group (commercially oriented articulation), or because the event provided an opportunity to showcase young athletic/musical talent and inspire upcoming athletes/musicians in line with the Adidas philosophy (noncommercially oriented articulation). An Adidas hyperlink at the bottom of the page led to the second Web page, which was constructed as a fictitious section of the Adidas Web site.

The second Web page provided the basis for the leverage manipulation. It outlined information about the general Adidas philosophy and corporate vision, before giving either additional information describing Adidas's values (forming the basis of the nonactivational Web site condition) or additional information describing Adidas's sponsorship philosophy (forming the basis of the activational Web site condition). The nonactivational condition outlined information typical of an "About Us" section of a Web site. The activational condition outlined information stating that sponsoring events was in line with the Adidas philosophy and noted that the event (relay event or music festival) was in line with Adidas's values. At the bottom of this page was a link to the third Web page.

The third Web page was an extension of the nonactivational and activational manipulations. In the nonactivational condition the page displayed additional information about Adidas (strategy information and management profiles, again similar to what is typically found under an "About Us" link on a Web site). In the activational condition the page displayed additional information about the event (competing athletes and their sports record profiles, or performing bands and their music history profiles). A link at the bottom of this page led to the end instruction page. It should be noted that the activational Web pages were not simply an extension of the articulation concept because articulation relates to the provision of an explanation, whereas activation here involved placing eventrelated information on the sponsor's Web site. Although elements of each set of Web pages varied, all pages were comparable in terms of layout, sentence and paragraph lengths, and Adidas name mentions.

\section{Procedure}

Students participated in the study as part of a marketing course in a teachingoriented computer laboratory. Prior to beginning the task, participants completed a two-page questionnaire designed to gather demographic information, together with Internet usage and brand familiarity information. They then navigated one of the eight experimental Web sites based on the computer at which they sat when they arrived. Directly after navigation, participants completed a second two-page questionnaire that contained measures to gauge perceptions of sponsor-event congruence, experience with the type of event described, attitudes toward Adidas as a brand, and attitudes toward Adidas as a company. These attitudinal measures were used as the Time 1 (no delay) measures. Seven days after navigation of the Web site, in the same class timeslot, participants completed a third two-page questionnaire where they again indicated their attitudes toward Adidas as a brand and toward Adidas as a company. These were used as the Time 2 (7-day delay) measures. Following this, participants were debriefed. 


\section{Measures}

Brand Familiarity (Measured Prior to Navigation). Brand familiarity was assessed by asking participants to list the three athletic footwear brands with which they were most familiar. This data served as a check to ensure participants had familiarity with Adidas as the chosen sponsor.

Internet Usage (Measured Prior to Navigation). Internet usage was measured with three Likert-type scale items, and was included for use as a covariate. The items used were "I use the Internet to find information for work/study purposes," "I use the Internet to find information for personal/leisure purposes," and "I use the Internet to aid my consumer-related decision making" $($ Cronbach's alpha $=0.714)$. These were rated on 7-point scales anchored at very frequently and very infrequently, and an average Internet usage value was obtained for each participant by averaging across the three responses. These items were developed for this study.

Perceived Congruence (Measured at Time 1). To assess perceptions of sponsor-sponsee congruence as a manipulation check, eight 7-point semantic differential scale items were used, with anchors of negative/positive, favorable / unfavorable, bad/good, complementary/not complementary, inappropriate / appropriate, illogical/logical, well matched / poorly matched, well suited/poorly suited (Cronbach's alpha $=0.941$ ). These items were taken from Roy and Cornwell (2003), and each participant's responses were averaged to give a perceived congruence measure.

Event Experience (Measured at Time 1). Based on the work of Roy and Cornwell (2004), which showed that perceptions of sponsor-sponsee congruence varies with knowledge of the event, a measure of event experience was collected for use as a second covariate. This was measured using three Likert-type scale items, namely, "I have had a lot of experience with the type of event described on the Web site," "I am highly knowledgeable about the type of event described on the Web site," and "I would describe myself as being familiar with the type of event described on the Web site" (Cronbach's alpha $=0.890$ ). These were rated on 7-point scales anchored at strongly agree and strongly disagree, and were adapted from the work of Beatty and colleagues (Beatty \& Smith, 1987; Beatty \& Talpade, 1994). Each participant's responses were averaged to give an event experience value.

Attitude Toward Sponsor (Measured at Time 1 and Time 2). The concept of "sponsor" was broken into the two levels of brand and company, both to ensure that the focus of responses was the same across participants and to check for differential effects. Attitude toward the Adidas brand was measured with three 7-point semantic differential scale items with anchors of negative/positive, bad/good, favorable/unfavorable (Time 1 Cronbach's alpha $=.878$, Time 2 Cronbach's alpha $=.855)$. These items were taken from Muehling and Laczniak (1988), with similar items having been used in a number 
of other sponsorship studies (e.g., McDaniel \& Kinney, 1998; Roy \& Cornwell, 2003; Ruth \& Simonin, 2003). Attitude toward Adidas as a company was measured with five 7-point semantic differential scale items with anchors of financially unstable / financially stable, disreputable / reputable, untrustworthy / trustworthy, unestablished/established, short-run oriented/long-run oriented (Time 1 Cronbach's alpha $=.834$, Time 2 Cronbach's alpha $=.893$ ), which were taken from Boulding and Kirmani (1993). An overall value for each of the attitudinal measures (brand and company) was obtained by averaging across the relevant scale items for each participant.

\section{RESULTS}

\section{Brand Familiarity}

In terms of athletic footwear brands, participants showed a high level of familiarity with Adidas. As a first choice in listing their three most familiar brands, $16.7 \%$ of participants listed Adidas. This figure increased to 53.5\% for the top two brands listed and to $81.6 \%$ for the top three brands. From this it was concluded that Adidas was quite a salient brand among participants, and that differential levels of familiarity should not cause problems across conditions.

\section{Event and Brand Congruence}

To check that the greater and lesser congruence conditions were perceived as such by participants, an independent-groups $t$-test was performed. Results showed that the relay event sponsorship was perceived to be significantly more congruent than the music festival sponsorship, $t(112)=6.602, p<.001(M \mathrm{~s}=5.775$ and 4.479), and thus that the congruence manipulation was satisfactory.

\section{Attitudes Toward Adidas as a Brand and Toward Adidas as a Company}

To investigate whether attitudes toward Adidas as a brand and toward Adidas as a company varied following exposure to the Web site (with no delay and after a 7-day delay), a repeated measures multivariate analysis of covariance was used, with a 2 (leverage) $\times 2$ (congruence) $\times 2$ (articulation) $\times 2$ (time of testing) mixed factorial design. Leverage, congruence, and articulation were betweengroups independent variables, while time of testing (Time 1, Time 2 ) was a within-groups independent variable for both attitude toward the Adidas brand and attitude toward the Adidas company dependent variables. Internet usage and event experience were covariates.

Using Pillai's Trace as the multivariate test statistic, leverage was shown to relate significantly to the dependent variables, $F(2,103)=7.138, p=.001$, as was articulation, $F(2,103)=3.966, p=.022$. Congruence was marginally related to the dependent variables at the multivariate level, $F(2,103)=2.609, p=.078$. A significant multivariate relationship was also shown for both the Internet usage covariate, $F(2,103)=4.448, p=.014$, and the event experience covariate, $F(2,103)=5.138, p=.007$. 
Having controlled for the effects of Internet usage and event experience, univariate results showed a significant main effect of leverage for both attitude toward Adidas as a brand, $F(1,104)=7.479, p=.007$, and attitude toward Adidas as a company, $F(1,104)=14.243, p<.001$. Specifically, activational leveraging resulted in more favorable attitudinal ratings than nonactivational leveraging for the brand $(M \mathrm{~s}=5.885$ and 5.445) and for the company $(M \mathrm{~s}=6.113$ and 5.648). There was also a significant main effect of congruence on attitude toward both brand, $F(1,104)=4.355, p=.039$, and company-level measures, $F(1,104)=4.287, p=.041$, due to participants indicating more favorable attitudes toward Adidas following navigation of the high-congruence Web site than the low-congruence Web site for both the brand measures $(M \mathrm{~s}=5.835$ and $5.495)$ and the company measures $(M \mathrm{~s}=6.009$ and 5.752). Results also showed a significant effect of articulation at the brand level, $F(1,104)=7.997$, $p=.006$, which was marginally significant at the company level, $F(1,104)=$ $3.582, p=.061$. Here, the attitudinal means for the noncommercially oriented articulation condition were higher than for the commercially oriented articulation condition for brand $(M \mathrm{~s}=5.897$ and 5.433) and for company $(M \mathrm{~s}=5.999$ and 5.762). The first three hypotheses ( $\mathrm{H} 1, \mathrm{H} 2$, and $\mathrm{H} 3)$ were therefore supported. As described next, the fourth and fifth hypotheses (H4a, H4b, and H5) were also largely supported.

As predicted, time of testing did not interact with either congruence or articulation. This indicates that the congruence and articulation effects reported above were present immediately after Web site navigation (Time 1) and were still present when assessed again after seven days (Time 2). Time of testing and the leverage manipulation did not interact at the brand level, but did interact at the company level, $F(1,104)=4.326, p=.040$. This is shown in Figure 1. As expected, this was due to there being little difference in attitude between Time 1 and Time 2 for participants who had navigated the activational Web site $(M \mathrm{~s}=6.150$ and 6.076), but a marked decline in attitude between Time 1 and Time 2 for participants who had navigated the nonactivational Web site $(M \mathrm{~s}=5.821$ and 5.476).

A three-way interaction was found between leverage, congruence, and articulation, which was significant at the company level, $F(1,104)=4.132, p=.045$, but not at the brand level, $F<1$. This interaction is displayed in Figure 2 .

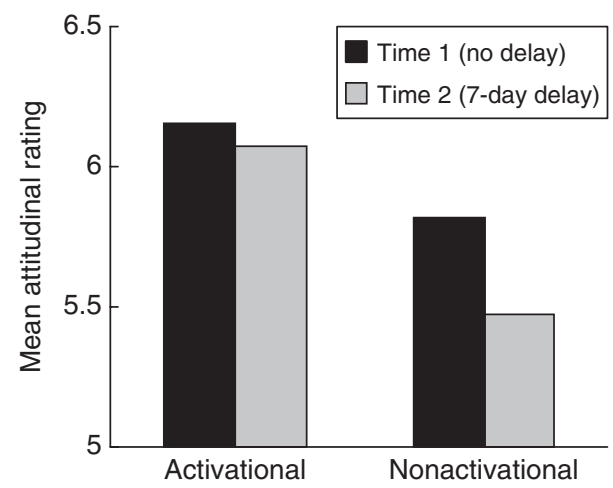

Figure 1. Mean attitudinal ratings toward company as a function of time of testing (no delay, 7-day delay) and Web site leverage (activational, nonactivational). 
Low-Congruence Sponsorship

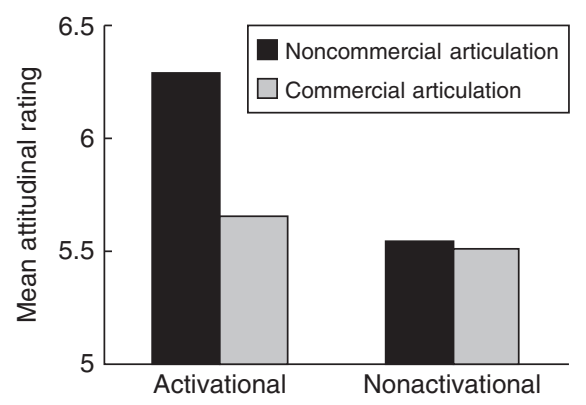

High-Congruence Sponsorship

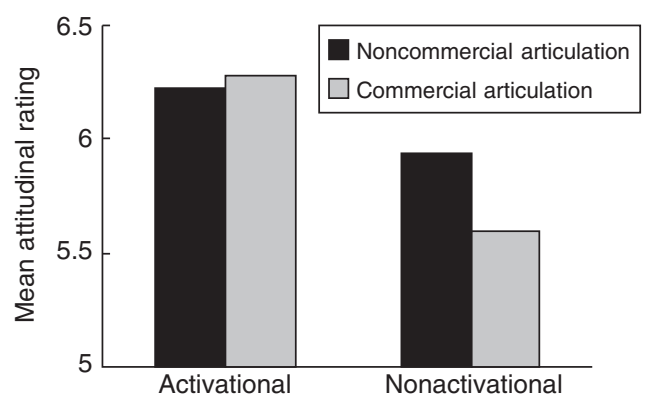

Figure 2. Mean attitudinal ratings toward company as a function of sponsor-sponsee congruence (low, high), articulation (noncommercially oriented, commercially oriented), and Web site leverage (activational, nonactivational).

As shown, for the low-congruence condition there was a large difference in attitudinal ratings across the noncommercially oriented and commercially oriented articulation activational Web sites $(M \mathrm{~s}=6.289$ and 5.659), but very little difference across the noncommercially oriented and commercially oriented articulation nonactivational Web sites $(M \mathrm{~s}=5.548$ and 5.510). The reverse was true for the high-congruence condition, where there was very little difference across the noncommercially oriented and commercially oriented articulation activational Web sites $(M \mathrm{~s}=6.219$ and 6.284$)$, with considerably more difference across the noncommercially oriented and commercially oriented articulation nonactivational Web sites $(M \mathrm{~s}=5.941$ and 5.594). The time of testing variable was not involved in this interaction, which indicates that these differences were present immediately after Web site navigation and remained when tested again after the 7-day delay. No other interactions were significant.

\section{DISCUSSION}

Results showed that there were differences in attitudes based on the leverage, congruence, and articulation manipulations as hypothesized. Specifically, when the sponsor's Web site was leveraged activationally, participants displayed more favorable attitudes toward the sponsor than when the Web site was leveraged nonactivationally (for both brand- and company-level measures). That is, when sponsor Web sites were designed to engage the sponsorship audience through incorporating event-specific information and through elaborating on the sponsorship, audiences responded more positively (at the company level this effect is qualified by the interaction to be discussed shortly). In terms of sponsorsponsee congruence, results showed that the high-congruence sponsorship was rated more favorably than was the low-congruence sponsorship both for brand and company. This finding is in line with what is often found in sponsorship research and indicates that congruence effects generalize to sponsorships leveraged on the Internet. Also as predicted, it was found that noncommercially oriented articulation led to more favorable attitudinal ratings than commercially oriented articulation. This effect was significant at the brand level and marginally significant at the company level. Thus, while Cornwell et al. (2006) 
reported that an articulatory statement explaining a sponsor's rationale for undertaking a sponsorship was able to enhance memory, the results of the current study indicate that the effects of such a statement on attitudinal ratings may be moderated by the commerciality of the explanation. In accordance with the work of Meenaghan and Shipley (1999) and Speed and Thompson (2000), the present results indicate that explaining a sponsorship investment to consumers in a commercially oriented manner may not be optimal for promoting positive attitudes.

As predicted, the current study also revealed that time of testing did not interact with congruence (at either the brand or company levels) nor with articulation (at either the brand or company levels). This indicates that the congruence and orientation of articulation effects reported above were present immediately after exposure and were still present after seven days. This may be because the nature of the sponsor-sponsee relationship and explanation of sponsor motive are salient characteristics of the sponsorship and thus can influence attitudes well after initial exposure.

Additionally, it was predicted that time of testing would interact with leverage such that attitudinal ratings associated with activational Web sites would be sustained across time while attitudinal ratings associated with nonactivational Web sites might decline. In line with the work of Petty and Cacioppo (e.g., Cialdini, Petty, \& Cacioppo, 1981; Petty \& Cacioppo, 1984; Petty, Cacioppo, \& Schumann, 1983), attitudes associated with activational Web sites were expected to be more favorable and more enduring because of their engaging and involving nature. Attitudes associated with nonactivational Web sites could potentially be favorable when tested immediately after navigation (e.g., if the Web site offers information that is in some way influential or relevant), but were expected to decline across time since nonactivational Web sites do not promote involvement with the sponsor. This interaction was present in company-level measures (see Figure 1), but not in brand-level measures, indicating that for brands the benefits of activation were present at both times. Given that the nonactivational Web site contained "About Us" type information relating to Adidas values and strategy and displayed management profiles, it is perhaps not surprising that company measures were initially affected. It may be that Web site navigation which involves exposure to such information is mostly beneficial for companylevel attitudes (albeit for a short time), and has little impact on brand-level attitudes. Nonetheless, after the seven-day delay those participants who had navigated the activational Web sites displayed more favorable attitudes than did those who navigated the nonactivational Web sites.

The study also revealed a three-way interaction between leverage, congruence, and articulation at the company level (see Figure 2). For the low-congruence sponsorship, noncommercially oriented articulation resulted in higher attitudinal ratings than did commercially oriented articulation when the sponsorship had been leveraged activationally, but there was no difference when the sponsorship was leveraged nonactivationally. In contrast, for the high-congruence sponsorship there was little difference in attitudes across the noncommercially oriented and commercially oriented articulation conditions when the sponsorship had been leveraged activationally, while noncommercially oriented articulation led to higher attitudinal ratings than commercially oriented articulation when the sponsorship had been leveraged nonactivationally. In essence, it appears that for the less congruent sponsorship, the beneficial effects of providing 
activational leverage were inhibited by the provision of a commercially oriented articulatory statement. For the high congruence sponsorship it appears that the noncommercially oriented statement helped to improve nonactivational Web site ratings (or conversely that the commercial orientation of the articulatory statement made the poorer attitudinal ratings of the nonactivational Web site worse). Having a commercially oriented articulatory statement for the high congruence activational Web site did not seem to lead to less positive attitudinal ratings - perhaps a high-congruence sponsorship combined with activational leveraging is able to override the negative impact of a commercially oriented articulatory statement.

Taking a more practical perspective, this finding suggests that if a sponsorsponsee relationship has low congruence, then activational leveraging may help to enhance attitudes, but only when a noncommercially oriented explanation is used. If a sponsor-sponsee relationship has high congruence, and is perhaps already seen for its commercial nature, then activational leverage activities might help to enhance attitudes even if the sponsorship is explained in commercially oriented terms. Explaining this sponsorship in noncommercially oriented terms may help to improve ratings when no activational leveraging is used. Perhaps consumers are more accepting of a commercial orientation for high-congruence sponsorships (in that these often already have marketing undertones), particularly when the sponsor is seen to give additional promotion to the event via its Web site. When sponsorships have low congruence, a noncommercial orientation may be more expected (since marketing benefits may be less obvious), which results in lower attitudinal ratings when a commercial orientation is made explicit, or when the sponsor is not seen to promote the event on its Web site.

\section{LIMITATIONS AND FUTURE RESEARCH}

Given the above discussion, an obvious limitation to the generality of the findings from this study is that it was based on a single youth-oriented brand, which was named as a sponsor for one of two largely youth-oriented events. However, that predictions were supported and in particular that there was a highly significant main effect for leverage, and that most attitudinal differences were sustained across time, suggests that the findings may be quite robust despite the limited nature of the stimuli employed. Relatedly, although event experience was controlled in the analysis, participants' liking for the events was not measured nor controlled, and thus it is possible that attitudes improved in part because of the leveraging of a sponsorship of a liked event. Future work that considers a broader range of brands, and correspondingly a broader range of events, will help to verify the patterns found in this study and to clarify the conditions under which the effects hold.

The study could also be criticized for requiring that participants navigate through predetermined Web pages rather than allowing self-determined navigation. As such, it could be questioned for truly being analogous to the situation of an event-interested consumer navigating a sponsor's Web site. However, the design is in line with previous sponsorship research where controlled Internet navigation tasks have been employed (e.g., Rodgers, 2004). Further, despite the artificiality of the task in this regard, the experimental design allowed for strict 
control over the types of information presented to participants and enabled comparisons to be made across conditions where only minor differences existed. Without having predetermined navigation routes for each condition, it would be difficult to validly interpret differences in attitudes between participants exposed to event-related brand information and participants exposed only to brand information. Moreover, those participants predisposed to rating Adidas favorably may be those more likely to navigate certain routes if self-determined. Future research making use of more elaborate Web sites, or allowing more naturalistic Web site navigation, may provide further insight into the issues raised in this paper.

\section{CONCLUSIONS}

With many firms now recognizing the need to develop a program of marketing communications to leverage their sponsorship investments, what becomes important for researchers is to develop an understanding of which activities are most effective in impacting the desired audiences. This paper has made a first attempt at clearly demarcating the terms leverage and activation when used in relation to sponsorship-linked marketing, in order to allow the separation of those activities that provide the opportunity for audiences to be engaged and interact with the sponsor, and those that are more likely to be passively processed. It has demonstrated that the Internet, despite seemingly being underutilized, can be an effective means for engaging the mass-media sponsorship audience. The study has shown that Web sites utilizing sponsorship activation are more effective in promoting favorable attitudes toward the sponsor than are Web sites that are nonactivational, and importantly, that these favorable attitudes can be present well after initial exposure. As a notable sideline issue, the study has also shown that in relation to attitudinal measures, sponsorship articulation research may be elucidated through considering potential moderators such as the commercial orientation of the explanations used.

\section{REFERENCES}

Assael, H. (2005). A demographic and psychographic profile of heavy Internet users and users by type of Internet usage. Journal of Advertising Research, 45, 93-123.

Beatty, S. E., \& Smith, S. M. (1987). External search effort: An investigation across several product categories. Journal of Consumer Research, 14, 83-95.

Beatty, S. E., \& Talpade, S. (1994). Adolescent influence in family decision making: A replication with extension. Journal of Consumer Research, 21, 332-341.

Becker-Olsen, K., \& Simmons, C. J. (2002). When do social sponsorships enhance or dilute equity? Fit, message source, and the persistence of effects. In S. M. Broniarczyk \& K. Nakamoto (Eds.), Advances in consumer research (Vol. 29, pp. 287-289). Provo, UT: Association for Consumer Research.

Becker-Olsen, K. L., \& Simmons, C. J. (2005). Not all sponsors are created equal. In G. Menon \& A. R. Rao (Eds.), Advances in consumer research (Vol. 32, p. 90). Provo, UT: Association for Consumer Research.

Boulding, W., \& Kirmani, A. (1993). A consumer-side experimental examination of signaling theory: Do consumers perceive warranties as signals of quality? Journal of Consumer Research, 20, 111-123. 
Brown, M. (2002, March). Experience counts. In-Store Marketing, p. 18.

Cialdini, R. B., Petty, R. E., \& Cacioppo, J. T. (1981). Attitude and attitude change. Annual Review of Psychology, 32, 357-404.

Cornwell, T. B., Roy, D. P., \& Steinard, E. A. (2001). Exploring managers' perceptions of the impact of sponsorship on brand equity. Journal of Advertising, 30, 41-51.

Cornwell, T. B., Weeks, C. S., \& Roy, D. P. (2005). Sponsorship-linked marketing: Opening the blackbox. Journal of Advertising, 34, 21-42.

Cornwell, T. B., Humphreys, M. S., Maguire, A. M., Weeks, C. S., \& Tellegen, C. L. (2006). Sponsorship-linked marketing: The role of articulation in memory. Journal of Consumer Research, 33, 312-321.

d'Astous, A., \& Bitz, P. (1995). Consumer evaluations of sponsorship programmes. European Journal of Marketing, 29, 6-22.

Ettore, B. (1993). Ambush marketing: Heading them off at the pass. Management Review, $82,53-57$.

Fry, A. (2006, November 22). Radio: Branding the airwaves. Marketing, p. 29.

Grohs, R., Wagner, U., \& Vsetecka, S. (2004). Assessing the effectiveness of sport sponsorships-An empirical investigation. Schmalenbach Business Review, 56, 119-138.

Gwinner, K., \& Eaton, J. (1999). Building brand image through event sponsorship: The role of image transfer. Journal of Advertising, 28, 47-57.

IEG. (2006). '06 activation spending to match all-time high. IEG Sponsorship Report, $25,1,4$.

IEG. (2007). Decision-maker survey: Sponsors report activation budgets have never been higher. IEG Sponsorship Report, 26, 1, 4.

Johar, G. V., \& Pham, M. T. (1999). Relatedness, prominence and constructive sponsor identification. Journal of Marketing Research, 36, 299-312.

McDaniel, S. R., \& Kinney, L. (1998). The implications of recency and gender effects in consumer response to ambush marketing. Psychology \& Marketing, 15, 385-403.

Meenaghan, T. (1991). The role of sponsorship in the marketing communications mix. International Journal of Advertising, 10, 35-47.

Meenaghan, T. (1996). Ambush marketing: A threat to corporate sponsorship. Sloan Management Review, 38, 103-113.

Meenaghan T., \& Shipley, D. (1999). Media effect in commercial sponsorship. European Journal of Marketing, 33, 328-347.

Migala Report. (2004, March). What's the buzz: Activation is the buzzword among marketers. Learn how to use activation to create marketing partnerships. Migala Report. http://www.migalareport.com/.

Miloch, K. S., \& Lambrecht, K. W. (2006). Consumer awareness of sponsorship at grassroots sport events. Sport Marketing Quarterly, 15, 147-154.

Muehling, D. D., \& Laczniak, R. N. (1988). Advertising's immediate and delayed influence on brand attitudes: Consideration across message-involvement levels. Journal of Advertising, 17, 23-34.

Parry, T. (2005, July 27). MLS All-Star game sees record number of sponsors. Promo Magazine. http://promomagazine.com/news/mls_sponsors_072705/index.html.

Performance Research. (2004). What sponsors want: Sponsorship decision makers' survey. http://www.performanceresearch.com/sponsor-survey.htm.

Petty, R. E., \& Cacioppo, J. T. (1984). The effects of involvement on responses to argument quantity and quality: Central and peripheral routes to persuasion. Journal of Personality \& Social Psychology, 46, 69-81.

Petty, R. E., Cacioppo, J. T., \& Schumann, D. (1983). Central and peripheral routes to advertising effectiveness: The moderating role of involvement. Journal of Consumer Research, 10, 135-146.

Quester, P. G., \& Thompson, B. (2001). Advertising and promotion leverage on arts sponsorship effectiveness (1998 Adelaide Festival of the Arts). Journal of Advertising Research, 4, 33-47. 
Rifon, N. J., Choi, S. M., Trimble, C. S., \& Li, H. (2004). Congruence effects in sponsorship: The mediating role of sponsor credibility and consumer attribution of sponsor motive. Journal of Advertising, 33, 29-42.

Rodgers, S. (2004). The effects of sponsor relevance on consumer reactions to Internet sponsorships. Journal of Advertising, 32, 67-76.

Roy, D. P., \& Cornwell, T. B. (2003). Brand equity's influence on responses to event sponsorships. Journal of Product and Brand Management, 12, 377-393.

Roy, D. P., \& Cornwell, T. B. (2004). The effects of consumer knowledge on responses to event sponsorships. Psychology \& Marketing, 21, 185-207.

Ruth, J. A., \& Simonin, B. L. (2003). Brought to you by Brand A and Brand B: Investigating multiple sponsors' influence on consumers' attitudes toward sponsored events. Journal of Advertising, 32, 19-30.

Ruth, J. A., \& Simonin, B. L. (2006). The power of numbers: Investigating the impact of event roster size in consumer response to sponsorship. Journal of Advertising, 35, $7-20$.

Simmons, C. J., \& Becker-Olsen, K. L. (2006). Achieving marketing objectives through social sponsorships. Journal of Marketing, 70, 154-169.

Sneath, J. Z., Finney, R. Z., \& Close, A. G. (2005). An IMC approach to event marketing: The effects of sponsorship and experience on customer attitudes. Journal of Advertising, $45,373-381$.

Speed, R., \& Thompson, P. (2000). Determinants of sports sponsorship response. Journal of the Academy of Marketing Science, 28, 226-238.

Steinberg, B. (2005, January 5). Sponsorships focus on "activation"; women's tennis tour deal with Sony Ericsson will let fans express themselves. Wall Street Journal (Eastern Edition), p. B2.

Correspondence regarding this article should be sent to: Clinton S. Weeks, School of Psychology, University of Queensland, Brisbane, Queensland, Australia 4072 (c.weeks@psy.uq.edu.au). 